\title{
Editorial
}

\section{Shin Research Excellence Awards: A partnership of The Geneva Association/International Insurance Society}

Joan Lamm-Tennant

Guy Carpenter \& Company, LLC, 1166 Avenue of the Americas, New York, NY 10036-2708, US. E-mail: joan.lamm-tennant@guycarp.com

The Geneva Papers (2013) 38, 137-139. doi:10.1057/gpp.2012.45

In partnership, The Geneva Association and the International Insurance Society (IIS) have combined efforts to achieve a broad global reach for prominent, practical insurance research-The Shin Research Excellence Awards. Presented annually, the research programme is designed to foster original, practically oriented, applied research in the insurance field addressing issues of concern to global insurance leaders by examining subjects which directly influence business operations and operational business issues on a practical level.

The integrity of the Shin Research Excellence Awards Program is based on a rigorous, dual review comprised of a pre-screening and refereed processes. After The Geneva Association and the IIS circulate a Request for Papers among academic institutions and forums, The Geneva Association compiles the submissions which it then pre-screens. Papers appropriate for the blind review conducted by the referee panel are then identified. The panel of judges, jointly appointed by the IIS and The Geneva Association, comprises business and academic insurance specialists whose singular function is to certify the academic quality and relevance of the selected research. The blind referee process is twofold, designed to establish both formulaic results and foster constructive commentary. Ultimately, the prescribed set of criteria deployed to the referee panel governs the selection process by establishing methodical conclusions. However, equally crucial to yielding substantive results is the referees' observations devised to qualify the research by compelling authors to substantiate their findings. Authors then integrate referees' comments into their papers. Subsequently, this interchange facilitates an enhancement of the research, thereby serving to enrich the quality of research by illuminating the practical implications of their research for the industry - a cornerstone of the Shin Research Excellence Awards Program.

Recognising that research anchors productive dialogue and serves as a catalyst for forward-looking innovation, the 2012 Shin Research Program focuses on Insurance Solutions for Developing Countries, a key theme that is attracting attention across industry sectors in both developing and developed markets.

Research submissions are reviewed by a Judging Committee represented by a diverse body of industry experts and the 2012 winning research focuses on microinsurance case studies and empirical data in the Pakistani and Nigerian marketplace. 
Microinsurance has garnered the attention of numerous insurance companies, industry bodies, academics, donors, investors and regulators. In turn, this has generated many schemes and a large volume of research and related reports. To date, insurers entering the market have revealed five key roadblocks:

1. achieving scale, efficiencies and profitability;

2. pricing in the absence of data;

3. effective distribution channels;

4. product designs that incent behaviour change; and

5. social impact measurement and education.

Despite these barriers, the rewards are significant—-by addressing the risk management and risk financing needs of underserved populations, economic development within emerging societies will become sustainable. And if products are properly designed to overcome these economic inhibitors, the underserved will advance their economic wellbeing.

In addition to the potential for positive economic impact in developing nations, microinsurance also presents an opportunity for sustainable and attractive returns for the contributors of risk capital. Success in microfinance/microcredit has debunked many beliefs regarding the financial dependability of low-income customers. Based on data from Mix Market, the top 50 Microfinance Institutions (MFIs), ranked by number of borrowers, report a return on equity in 2010 ranging from a gain of 52 per cent to a loss of 9.5 per cent. While the level of returns for some MFIs remains controversial, the range has converged over time, suggesting that a broad and competitive marketplace is developing. Drawing from this evidence, many believe similar results will evolve by developing a competitive marketplace that addresses the risk management and risk financing needs of the underserved. A broad marketplace already exists-Swiss $\mathrm{Re}$ estimates the global market for commercially viable microinsurance products to be 2.6 billion people and US\$40 billion in direct written premium.

Microinsurance can also incent reverse innovation, yet another benefit for the industry. Evidence suggests that the problems associated with contracting under uncertainty (moral hazard and asymmetric information) are similar in industrialised and emerging nations. However, the solutions to these problems in emerging markets must be uniquely addressed through product design. For example, index-based agriculture programmes and schemes render payment in seeds as opposed to currency. We also have evidence of successful health insurance schemes sold to all comers in communities with high incidence of HIV/AIDS subject to proof of treatment at a nearby clinic. By being forces of change to overcome these contracting problems differently, we learn new and more efficient techniques that can subsequently be applied in industrialised countries - reverse innovation.

Public/private partnerships laid the foundation for microinsurance, although the future relies on collaboration within the industry. Through collaboration, the industry can establish the foundation necessary for a competitive marketplace:

- a portfolio approach to profitability;

- metrics for financial and social impact; and

- feedback loops between metrics and product design. 
Microinsurance presents challenges, but the benefits are significant. It provides a clear social impact that allows underserved communities to achieve economic independence. It encourages further investment into emerging economies that have a private market response to risk. And microinsurance provides growth opportunities with attractive profits for the entire industry.

With 80 per cent of the world's population living in emerging markets there is a vast untapped demand for insurance. Microinsurance currently covers approximately 5 per cent of the potential market and therefore is quickly emerging as a significant driver of economic growth and profitability for insurers looking to expand their market share in developing markets while building a robust customer base for future expansion. The insightful research of Kitty Yao, of the University of Wisconsin at Madison, centred on the Development and Sustainability of Emerging Health Insurance Markets: Evidence from Microinsurance in Pakistan and that of Olajumoke Olaosebikan of the University of Bath focusing on The Determinants of the Profitability of Micro-Life Insurers in Nigeria aptly respond to the objective of the joint research programme to establish practical intelligence and identify solutions towards the development of emerging markets. 